\title{
Perfectionism and aggression following unintentional, ambiguous, and intentional provocation
}

\author{
Joachim Stoeber $^{1}$ (D) Anna Hadjivassiliou ${ }^{1}$ \\ Published online: 24 July 2020 \\ (C) The Author(s) 2020
}

\begin{abstract}
The social disconnection model of perfectionism posits that perfectionism is positively related to various indicators of social disconnection including hostility and aggression. Recent findings, however, indicate that only other-oriented and sociallyprescribed perfectionism are positively related to aggression, not self-oriented perfectionism. The present study $(N=271)$ further examined the perfectionism-aggression relationships using social vignettes differentiating aggression following unintentional, ambiguous, and intentional provocation. Results showed that - when the overlap between the perfectionism dimensions was controlled - only other-oriented perfectionism showed positive relationships with aggression across provocation situations. In contrast, socially prescribed perfectionism showed a positive relationship only with aggression following unintentional provocation, and self-oriented perfectionism showed a negative relationship. The findings suggest that, whereas people high in selforiented perfectionism tend to be unaggressive, people high in other-oriented perfectionism have a general tendency toward aggression, and people high in socially prescribed perfectionism show a hostile attribution bias.
\end{abstract}

Keywords Perfectionism $\cdot$ Social disconnection $\cdot$ Hostility $\cdot$ Aggression

Perfectionism is a prevalent personality disposition characterized by exceedingly high standards that are difficult, if not impossible to meet (Stoeber, 2018). A recent meta-analysis found that general levels of perfectionism have been increasing over the past decades, and more and more people show high levels of perfectionism (Curran \& Hill, 2019). Because high levels of perfectionism are associated with a range of psychopathological symptoms such as anxiety, depressive symptoms, obsessive-compulsive behaviors, and disordered eating (Limburg et al., 2017), perfectionisms may adversely affect people's mental health and well-being. Furthermore, perfectionism may adversely affects people's social lives.

According to the perfectionism social disconnection model (PSDM; Hewitt et al., 2006), perfectionism is positively related to various indicators of social disconnection including antisocial characteristics and behaviors that make it difficult for perfectionists to connect with others such as hostility and aggression (Barnett \& Johnston, 2016; Roxborough et al., 2012).

Joachim Stoeber

J.Stoeber@kent.ac.uk

1 School of Psychology, University of Kent, Canterbury, Kent CT2 7NP, UK
Perfectionism, however, is a multidimensional personality disposition (Frost et al. 1990; Hewitt \& Flett, 1991). In particular, Hewitt and Flett (1991) differentiate three dimensions capturing personal and social aspects of perfectionism: selforiented, other-oriented, and socially prescribed perfectionism. When examining the defining characteristics of the dimensions (Hewitt \& Flett, 1991, 2004), the key beliefs and expectations differentiating the three can be summarized as follows: Self-oriented perfectionism reflects beliefs that it is important to strive for perfection. People high in self-oriented perfectionism expect to be perfect. Other-oriented perfectionism reflects beliefs that it is important for others to strive for perfection. People high in other-oriented perfectionism expect others to be perfect. And socially prescribed perfectionism reflects beliefs that striving for perfection is important to others. People high in socially prescribed perfectionism believe that others expect them to be perfect, and that others will disapprove of them if they are not (Stoeber et al., 2020).

Whereas the PSDM originally focused on socially prescribed perfectionism only, it was recently expanded to also include self-oriented and other-oriented perfectionism (Sherry et al., 2016). According to the expanded PSDM, all three dimensions of perfectionism are positively related to indicators of social disconnection (see also Hewitt et al., 2017). Whereas studies have confirmed that this includes the 
dimension of self-oriented perfectionism (Smith et al., 2020), not all three perfectionism dimensions may be positively related to hostility and aggression. This is suggested by a number of studies indicating that only other-oriented and socially prescribed perfectionism consistently show positive relationships with hostility and aggression, but not self-oriented perfectionism. In fact, when the overlap between the three perfectionism dimensions is statistically controlled, self-oriented perfectionism may even show negative relationships with indicators of antisocial characteristics such as hostility and aggression (Stoeber, 2014, 2015; Stoeber et al., 2017). This goes in particular for aggression. Stoeber et al. (2017) examined different aspects of aggression and found that any positive relationships that self-oriented perfectionism showed with aggression disappeared when the overlap with the other two forms of perfectionism was statistically controlled, and selforiented perfectionism even showed a significant negative relationship with physical aggression. In contrast, both otheroriented and socially prescribed perfectionism maintained their significant positive relationships.

These findings are relevant for our understanding perfectionism and social disconnection because aggression is a strong indicator of hostility. (People can be hostile without being aggressive, but aggression against others always implies hostility.) However, whereas there are numerous studies on perfectionism and aggression, so far only two studies have investigated perfectionism and aggression in relation to social disconnection (Barnett \& Johnston, 2016; Stoeber et al., 2017). Moreover, the vast majority of studies on perfectionism and aggression have focused on physical versus verbal aggression (e.g., Vicent et al., 2017), but so far no study has examined perfectionism and aggression in situations with different degrees of provocation (Tremblay \& Belchevski, 2004).

Consequently, the aim of the present study was to expand on the previous findings and further examine the perfectionism-aggression relationships by exploring perfectionism's relationships with aggression following intentional, unintentional, and ambiguous provocation - that is, aggression in situations where (a) an instigator clearly intended to provoke, (b) an instigator clearly intended not to provoke, and (c) the presence of an intention was ambiguous - which can be used to differentiate a general propensity toward aggression from a hostile interpretation bias (Tremblay \& Belchevski, 2004). Based on previous findings on the relationships the three dimensions of perfectionism show with hostility and aggression (Stoeber, 2014, 2015; Stoeber et al., 2017), we expected other-oriented perfectionism and socially prescribed perfectionism to show positive relationships with aggression after provocation, but not self-oriented perfectionism. Else, as this was the first study examining perfectionism and aggression following different degrees of provocations, the study was largely exploratory.

\section{Method}

\section{Participants and Procedure}

Following Monte-Carlo analyses indicating that estimates of correlations stabilize with sample sizes approaching 250 (Schönbrodt \& Perugini, 2013), we aimed to recruit a sample of $N>250$. Participants were recruited from two sources: 134 undergraduate students from our school's Research Participation Scheme in exchange for course credit, and - to increase the diversity of the sample (Gosling et al., 2010) - 141 Internet users from various online forums (e.g., Facebook, In-Mind, Psychological Research on the Net) in exchange for a chance to win one of five $£ 10$ Amazon ${ }^{\circledR}$ vouchers. The total sample comprised 275 participants (68 male, 203 female, 2 other, 2 preferred not to say) with a mean age of 27.4 years $(S D=$ 14.2; range: $17-85$ years). Asked for their ethnicity, participants self-identified as White (69\%), Asian (16\%), Black $(7 \%)$, mixed race $(6 \%)$, and other (3\%). Participants completed all measures online using the School's Qualtrics ${ }^{\circledR}$ platform and were required to respond to all questions (so to prevent missing data) which was approved by the relevant ethics committee.

\section{Measures}

Perfectionism The Multidimensional Perfectionism Scale (MPS; Hewitt \& Flett, 2004) was used to measure - with 15 items each - self-oriented perfectionism (e.g., "I demand nothing less than perfection of myself"), other-oriented perfectionism ("If I ask someone to do something, I expect it to be done flawlessly"), and socially prescribed perfectionism ("People expect nothing less than perfection from me"). Participants received the standard instruction of the MPS ("Listed below are a number of statements concerning personal characteristics and traits...") responding on a scale from 1 (strongly disagree) to 7 (strongly agree). The MPS is one of the most widely-used measures of multidimensional perfectionism and has demonstrated reliability and validity across numerous studies (e.g., Hewitt \& Flett, 1991, 2004; Stoeber, 2014).

Aggression The social vignettes from Tremblay and Belchevski (2004) were used to measure - with eight vignettes each - aggression following unintentional, ambiguous, and intentional provocation each followed by six ratings with participants responding on a scale from 0 to 10 (see Appendix 1 for details). Tremblay and Belchevski's measure of aggression has been used in a number of studies where it has demonstrated reliability and validity (e.g., HelfritzSinville \& Stanford, 2014; Miller et al., 2011; Tremblay \& Belchevski, 2004). 


\section{Statistical Software}

All analyses were conducted using IBM SPSS ${ }^{\circledR} 25$ except for the multilevel analyses for which we used Mplus 8.3 (Muthén \& Muthén 1998-2017).

\section{Data Screening and Preliminary Analyses}

Because multivariate outliers distort the results of correlation and regression analyses, four participants showing a significant Mahalanobis distance $(p<.001)$ were excluded from the analyses (Tabachnick \& Fidell, 2007), so the final sample comprised 271 participants. Cronbach's alphas were used to examine the measures' reliability. All measures showed satisfactory alphas $\geq .77$ (see Table 1 ).

Next, we conducted a repeated-measures ANOVA on the three aggression measures. Results showed a highly significant effect of provocation, $F(2,269)=173.25, p<.001$, partial $\eta^{2}=.56$, with large and significant mean differences in the expected direction - mean aggression following unintentional provocation $<$ mean aggression following ambiguous provocation $<$ mean aggression following intentional provocation (see again Table 1) - indicating that participants clearly differentiated between aggression following unintentional, ambiguous, and intentional provocation as the vignettes intended (Tremblay \& Belchevksi, 2004).

Finally, we examined if there were differences between the two subsamples (with subsample coded $1=$ Internet users, $0=$ undergraduate students). Results showed that Internet users reported overall lower aggression than undergraduate students, but showed no differences in perfectionism (see Table 1). Because perfectionism was the predictor in all our models and showed no subsample differences, subsample was disregarded in all consecutive analyses.

\section{Results}

First, we examined the three perfectionism dimensions' bivariate correlations with the three measures of aggression (see Table 1). As expected, only other-oriented and socially prescribed perfectionism showed significant positive correlations with aggression. Furthermore, only other-oriented perfectionism showed significant correlations across all provocation situations.

Next, we conducted multiple regressions to examine the unique relationships of the three perfectionism dimensions (see Table 2, Multiple regressions). To this aim, the three dimensions were entered simultaneously to predict aggression following unintentional, ambiguous, and intentional provocation. Whereas the pattern of significant relationships found in the bivariate correlations did not change for aggression following intentional provocation, it changed for the other two provocation situations. Regarding unintentional provocation, self-oriented perfectionism now showed a negative relationship with aggression. Regarding ambiguous provocation, only other-oriented perfectionism continued to show a positive relationship with aggression.

To further explore the differential pattern of unique relationships the three perfectionism dimensions showed in the multiple regressions, we conducted multilevel analyses to probe for significant perfectionism $\times$ provocation interactions on aggression followed up by pairwise comparisons. The reason we conducted multilevel analyses using Mplus was that

Table 1 Descriptive statistics, Cronbach's alphas, and bivariate correlations

\section{Correlation}

\begin{tabular}{|c|c|c|c|c|c|c|c|c|c|}
\hline Variable & $M$ & $S D$ & $\alpha$ & 1 & 2 & 3 & 4 & 5 & 6 \\
\hline \multicolumn{10}{|l|}{ Perfectionism } \\
\hline 1. Self-oriented perfectionism & 4.44 & 1.05 & .91 & & & & & & \\
\hline 2. Other-oriented perfectionism & 3.69 & 0.71 & .77 & $.49 * * *$ & & & & & \\
\hline 3. Socially prescribed perfectionism & 3.63 & 0.83 & .85 & $.45 * * *$ & $.31 * * *$ & & & & \\
\hline \multicolumn{10}{|l|}{ Aggression following } \\
\hline 4. Unintentional provocation & 2.03 & 1.31 & .88 & .02 & $.22 * * *$ & $.16^{* *}$ & & & \\
\hline 5. Ambiguous provocation & 2.54 & 1.44 & .89 & .10 & $.24 * * *$ & $.13^{*}$ & $.85^{* * * *}$ & & \\
\hline 6. Intentional provocation & 3.37 & 1.69 & .93 & .10 & $.23 * * *$ & .08 & $.71 * * *$ & $.87 * * *$ & \\
\hline Subsample & - & - & - & .04 & .02 & -.05 & $-.17 * *$ & $-.23 * * *$ & $-.27 * * *$ \\
\hline
\end{tabular}

Note: $N=271$. Variables are average item scores. $\alpha=$ Cronbach's alpha. Subsample was coded $1=$ Internet users, $0=$ undergraduate students

$* p<.05$

$* * p<.01$

$* * * p<.001$ 
Table 2 Summary of results from the multiple regressions and multilevel analyses predicting aggression following provocation

\begin{tabular}{|c|c|c|c|c|c|c|c|c|}
\hline & \multicolumn{6}{|c|}{ Multiple regressions } & \multirow{2}{*}{\multicolumn{2}{|c|}{ Multilevel analyses }} \\
\hline & \multicolumn{2}{|c|}{$\begin{array}{l}\text { Unintentional } \\
\text { provocation }\end{array}$} & \multicolumn{2}{|c|}{$\begin{array}{l}\text { Ambiguous } \\
\text { provocation }\end{array}$} & \multicolumn{2}{|c|}{$\begin{array}{l}\text { Intentional } \\
\text { provocation }\end{array}$} & & \\
\hline & $R^{2}$ & $\beta$ & $R^{2}$ & $\beta$ & $R^{2}$ & $\beta$ & Inter-action & Pairwise comparisons \\
\hline Regression model & $.077 * * *$ & & $.063 * * *$ & & $.051 * *$ & & & \\
\hline Self-oriented perfectionism & & $-.18^{*}$ & & -.05 & & -.02 & $.13^{*}$ & $\mathrm{UP}<\mathrm{AP}, \mathrm{UP}<\mathrm{IP}, \mathrm{AP}=\mathrm{IP}$ \\
\hline Other-oriented perfectionism & & $.25 * * *$ & & $.24 * * *$ & & $.23 * * *$ & .05 & $\mathrm{UP}=\mathrm{AP}=\mathrm{IP}$ \\
\hline Socially prescribed perfectionism & & $.16^{*}$ & & .08 & & .02 & $-.11^{*}$ & $\mathrm{UP}=\mathrm{AP}, \mathrm{UP}>\mathrm{IP}, \mathrm{AP}=\mathrm{IP}$ \\
\hline
\end{tabular}

Note: $N=271 . \beta=$ standardized regression weight. Interaction: within-level standardized Bayesian estimates of the perfectionism $\times$ provocation (unintentional, ambiguous, intentional) interaction on aggression. Pairwise comparisons: estimated differences between the regression weights for unintentional provocation (UP), ambiguous provocation (AP), and intentional provocation (IP) with smaller-than $(<)$ and larger-than (>) indicating significant differences $(p<.05)$

$* p<.05$

$* * p<.01$

$* * * p<.001$

provocation was a within-participants factor (i.e., provocation was clustered within participants) and therefore standard moderated regression analyses for testing interaction effects using SPSS could not be applied (see Appendix 2 for details). Results showed significant perfectionism $\times$ provocations interactions for self-oriented and socially prescribed perfectionism, but not other-oriented perfectionism (see Table 2, Multilevel analyses) indicating that how self-oriented and socially prescribed perfectionism predicted aggression was dependent on the degree of perceived intention of provocation. In particular, self-oriented perfectionism predicted significantly lower levels of aggression following unintentional provocation (compared to ambiguous and intentional provocation) whereas socially prescribed perfectionism predicted significantly higher levels of aggression following unintentional provocation (compared to intentional provocation). In contrast, other-oriented perfectionism always predicted higher levels of aggression regardless of the degree of perceived intention of provocation.

\section{Discussion}

Expanding on previous research on self-oriented, other-oriented, and socially prescribed perfectionism and aggression by examining aggression following different degrees of provocation, the present study's findings confirmed previous research that only other-oriented and socially prescribed perfectionism consistently show positive relationships with aggression, but not self-oriented perfectionism (cf. Stoeber et al. 2017). Furthermore, the present findings suggest that the perfectionism-aggression link is particularly strong for other-oriented perfectionism because only other-oriented perfectionism showed positive relationships with aggression following unintentional, ambiguous, and intentional provocation whereas socially prescribed perfectionism showed a positive relationship only with aggression following unintentional provocation (and to a lesser extent with aggression following ambiguous provocation).

The findings have implications for the expanded PSDM as well as our understanding of multidimensional perfectionism and aggression. As regards self-oriented perfectionism, the findings confirm previous findings that self-oriented perfectionism is unrelated to aggression suggesting that the social disconnection experienced in self-oriented perfectionism may not be a function of interpersonal hostility, but may have other causes (Hewitt et al., 2017; Sherry et al., 2016). As regards other-oriented and socially prescribed perfectionism, however, our findings support claims that perfectionism is related to interpersonal hostility confirming previous findings that both dimensions consistently show positive relationships with aggression. In addition, our findings suggest that people who believe that others expect them to be perfect may have a hostile attribution bias (Tremblay \& Belchevski, 2004) because socially prescribed perfectionism showed positive relationships with aggression only following unintentional and ambiguous provocation. In contrast, people who expect others to be perfect may have a general propensity toward aggression because other-oriented perfectionism showed positive relationships with aggression regardless of whether an instigator intended to provoke, did not intend to provoke, or whether the intention was unclear.

The present study has a number of limitations. First, the study was largely exploratory, so future studies need to replicate the present findings before firm conclusions can be drawn. Second, despite the recruitment process aiming for 
greater diversity, our sample was predominantly female (74\%) and White $(69 \%)$. Future studies may therefore want to reexamine the findings with samples that include a greater proportion of males and show greater ethnic diversity. Second, the effect sizes of the relationships between perfectionism and aggression were only small to medium-sized (Cohen, 1992): No correlation was larger than .24, and the three perfectionism dimension together explained at most $7.7 \%$ variance in aggression (see Tables 1 and 2). Note, however, that in individual differences research, correlations of .20 should not be considered small, but typical (Gignac \& Szodorai, 2016) and that aggression is a consequential outcome, so the present findings are still important (Ozer \& Benet-Martínez, 2005). Finally, the study focused on Hewitt and Flett's (1991) model of perfectionism. Even though theirs is one of the most widelyresearched models of multidimensional perfectionism, future studies should expand the present research to other multidimensional models that capture personal and social aspects of perfectionism (e.g., Smith et al., 2016).

Despite these limitations, we think that our findings make a contribution to the understanding of multidimensional perfectionism, social disconnection, and aggression by suggesting that it is not only important to differentiate personal and social aspects of perfectionism when examining perfectionismaggression relationships, but also personal interpretations of social situations when examining aggression.

Acknowledgements We would like to thank Anna Brown for helpful guidance and advice regarding the multilevel analyses.

\section{Compliance with Ethical Standards}

Conflict of Interest On behalf of all authors, the corresponding author states that there is no conflict of interest.

\section{Appendix A}

Tremblay and Belchevski's Measure of Aggression Tremblay and Belchevski (2004) measured aggression using 24 social vignettes of which eight each measured aggression following unintentional, ambiguous, and intentional provocation, for example, "Your friends go out for lunch without inviting you. When they see you after lunch they tell you that they thought you had gone home early and apologize for not inviting you" (unintentional), "You walk by three boys playing street hockey. As you pass them you hear one laughing, then the rubber ball hits you in the head" (ambiguous), and "You are at the movies with your friends and some teenagers behind you keep kicking the back of your seat. One of your friends gives them a dirty look but they continue kicking your seat even harder" (intentional).

Each vignette was followed by six ratings. First, participants were asked how angry they would be about the situation and rated their responses on a scale from 0 (not angry at all) to 10 (extremely angry). Then they were asked how likely they were to (a) "Express to them that you are angry," (b) "Be rude to them," (c) "Yell or swear at them," (d) "Threaten them if the situation were not resolved," and (e) "Use physical force (e.g., push or grab) if the situation were not resolved" - with "them" replaced by "his" or "her" where appropriate - and participants rated their responses on a scale from 0 (not at all likely) to 10 (extremely likely). Responses were averaged across the six ratings and eight vignettes to measure aggression following unintentional, ambiguous, and intentional provocation.

\section{Appendix B}

Multilevel Analyses The multilevel analyses we conducted are comparable to moderated regression analyses for testing interactions of continuous variables with categorical variables representing between-participants factors (Aiken \& West, 1991; Cohen et al., 2003). However, because in the present case, the categorical variable - provocation (unintentional, ambiguous, intentional) - was a within-participants factor, standard regression analyses could not be applied and multilevel analyses were required (Luke, 2004). Consequently, we created a two-level data set in which aggression was the level1 variable representing the dependent variable, provocation ( coded $0=$ unintentional, $1=$ ambiguous, $2=$ intentional) represented the level-1 units and participants the level-2 units making participant the cluster variable - and the perfectionism scores $(\mathrm{SOP}=$ self-oriented perfectionism, $\mathrm{OOP}=$ other-oriented perfectionism, and SPP = socially prescribed perfectionism) were level-2 variables. Analyzing the data using Mplus resulted in an intraclass correlation of .698 indicating that conducting multilevel analyses was appropriate.

To test the perfectionism $\times$ provocation interactions for significance, we then specified a two-level regression analysis for a continuous dependent variable with a random slope (see Muthén \& Muthén, 1998-2017, pp. 275-279, Example 9.2). In this, the slope of provocation predicting aggression was modeled as a random variable; and then SOP, OOP, and SPP were modeled as predictors of the slope. Only SOP and SPP emerged as significant predictors of the slope - meaning that how provocation predicted aggression was dependent on participants' levels of SOP and SPP - indicating significant SOP $\times$ provocation and SPP $\times$ provocation interactions on aggression (see Table 2, Multilevel analyses, Interaction).

To probe which differences between conditions were responsible for the significant interactions, we then repeated the analysis three times each time excluding a different provocation condition from the analysis (e.g., excluding $0=$ unintentional from the analysis to probe the difference between $1=$ ambiguous and $2=$ intentional) to see for what slopes - now representing pairwise comparisons of regression weights - 
SOP and SPP remained significant predictors, and then summarized the significant differences in Table 2 (see Table 2, Multilevel analyses, Pairwise comparisons).

Open Access This article is licensed under a Creative Commons Attribution 4.0 International License, which permits use, sharing, adaptation, distribution and reproduction in any medium or format, as long as you give appropriate credit to the original author(s) and the source, provide a link to the Creative Commons licence, and indicate if changes were made. The images or other third party material in this article are included in the article's Creative Commons licence, unless indicated otherwise in a credit line to the material. If material is not included in the article's Creative Commons licence and your intended use is not permitted by statutory regulation or exceeds the permitted use, you will need to obtain permission directly from the copyright holder. To view a copy of this licence, visit http://creativecommons.org/licenses/by/4.0/.

\section{References}

Aiken, L. S., \& West, S. G. (1991). Multiple regression: Testing and interpreting interactions. Newbury Park: Sage.

Barnett, M. D., \& Johnson, D. M. (2016). The perfectionism social disconnection model: The mediating role of communication styles. Personality and Individual Differences, 94, 200-205.

Cohen, J. (1992). A power primer. Psychological Bulletin, 112, 155-159.

Cohen, J., Cohen, P., West, S. G., \& Aiken, L. S. (2003). Applied multiple regression/correlation analysis for the behavioral sciences (3rd ed.). Mahwah: Lawrence Erlbaum Associates.

Curran, T., \& Hill, A. P. (2019). Perfectionism is increasing over time: A meta-analysis of birth cohort differences from 1989 to 2016. Psychological Bulletin, 145, 410-429.

Frost, R. O., Marten, P., Lahart, C., \& Rosenblate, R. (1990). The dimensions of perfectionism. Cognitive Therapy and Research, 14, 449468.

Gignac, G. E., \& Szodorai, E. T. (2016). Effect size guidelines for individual differences researchers. Personality and Individual Differences, 102, 74-78.

Gosling, S. D., Sandy, C. J., John, O. P., \& Potter, J. (2010). Wired but not WEIRD: The promise of the internet in reaching more diverse samples. Behavioral and Brain Sciences, 33, 94-95.

Helfritz-Sinville, L. E., \& Stanford, M. S. (2014). Hostile attribution bias in impulsive and premeditated aggression. Personality and Individual Differences, 56, 45-50.

Hewitt, P. L., \& Flett, G. L. (1991). Perfectionism in the self and social contexts: Conceptualization, assessment, and association with psychopathology. Journal of Personality and Social Psychology, 60, 456-470.

Hewitt, P. L., \& Flett, G. L. (2004). Multidimensional perfectionism scale (MPS): Technical manual. Toronto: Multi-Health Systems.

Hewitt, P. L., Flett, G. L., Sherry, S. B., \& Caelian, C. (2006). Trait perfectionism dimensions and suicidal behavior. In T. E. Ellis (Ed.), Cognition and suicide: Theory, research, and therapy (pp. 215-235). Washington, DC: American Psychological Association.

Hewitt, P. L., Flett, G. L., \& Mikail, S. F. (2017). Perfectionism: A relational approach to conceptualization, assessment, and treatment. New York: Guilford.
Limburg, K., Watson, H. J., Hagger, M. S., \& Egan, S. J. (2017). The relationship between perfectionism and psychopathology: A metaanalysis. Journal of Clinical Psychology, 73, 1301-1326.

Luke, D. A. (2004). Multilevel modeling. Thousand Oaks: Sage.

Miller, J. D., Hoffman, B. J., Gaughan, E. T., Gentile, B., Maples, J., \& Campbell, W. K. (2011). Grandiose and vulnerable narcissism: A nomological network analysis. Journal of Personality, 79, 10131042.

Muthén, L. K., \& Muthén, B. O. (1998-2017). Mplus user's guide (8th ed.). Los Angeles: Authors.

Ozer, D. J., \& Benet-Martínez, V. (2005). Personality and the prediction of consequential outcomes. Annual Review of Psychology, 57, 401421.

Roxborough, H. M., Hewitt, P. L., Kaldas, J., Flett, G. L., Caelian, C. M., Sherry, S. B., \& Sherry, D. L. (2012). Perfectionistic self-presentation, socially prescribed perfectionism, and suicide in youth: A test of the perfectionism social disconnection model. Suicide and Lifethreatening Behavior, 42, 217-233.

Schönbrodt, F. D., \& Perugini, M. (2013). At what sample size do correlations stabilize? Journal of Research in Personality, 47, 609-612.

Sherry, S. B., Mackinnon, S. P., \& Gautreau, C. M. (2016). Perfectionists don't play nicely with others: Expanding the social disconnection model. In F. M. Sirois \& D. S. Molnar (Eds.), Perfectionism, health, and well-being (pp. 225-243). New York: Springer.

Smith, M. M., Saklofske, D. H., Stoeber, J., \& Sherry, S. B. (2016). The big three perfectionism scale: A new measure of perfectionism. Journal of Psychoeducational Assessment, 34, 670-687.

Smith, M. M., Sherry, S. B., Vidovic, V., Hewitt, P. L., \& Flett, G. L. (2020). Why does perfectionism confer risk for depressive symptoms? A meta-analytic test of the mediating role of stress and social disconnection. Journal of Research in Personality, 86, 103954.

Stoeber, J. (2014). How other-oriented perfectionism differs from selforiented and socially prescribed perfectionism. Journal of Psychopathology and Behavioral Assessment, 36, 329-338.

Stoeber, J. (2015). How other-oriented perfectionism differs from selforiented and socially prescribed perfectionism: Further findings. Journal of Psychopathology and Behavioral Assessment, 37, 611623.

Stoeber, J. (2018). The psychology of perfectionism: An introduction. In J. Stoeber (Ed.), The psychology of perfectionism: Theory, research, applications (pp. 3-16). London: Routledge.

Stoeber, J., Lalova, A. V., \& Lumley, E. J. (2020). Perfectionism, (self)compassion, and subjective well-being: A mediation model. Personality and Individual Differences, 154, 109708.

Stoeber, J., Noland, A. B., Mawenu, T. W. N., Henderson, T. M., \& Kent, D. N. P. (2017). Perfectionism, social disconnection, and interpersonal hostility: Not all perfectionists don't play nicely with others. Personality and Individual Differences, 119, 112-117.

Tabachnick, B. G., \& Fidell, L. S. (2007). Using multivariate statistics (5th ed.). Boston: Pearson.

Tremblay, P. F., \& Belchevski, M. (2004). Did the instigator intend to provoke? A key moderator in the relation between trait aggression and aggressive behavior. Aggressive Behavior, 30, 409-424.

Vicent, M., Inglés, C. J., Sanmartín, R., Gonzálvez, C., \& GarcíaFernández, J. M. (2017). Perfectionism and aggression: Identifying risk profiles in children. Personality and Individual Differences, $112,106-112$.

Publisher's Note Springer Nature remains neutral with regard to jurisdictional claims in published maps and institutional affiliations. 